\title{
CONSTRUCCIÓN Y DECONSTRUCCIÓN DEL CUERPO. ANÁLISIS DE FIGURINAS CERÁMICAS. UNA APROXIMACIÓN METODOLÓGICA
}

\author{
CONSTRUCTION AND DECONSTRUCTION OF THE BODY. \\ ANALYSIS OF CERAMIC FIGURINES. A METHODOLOGICAL APPROACH
}

LAURA VILAS

En este trabajo se presenta el análisis de un conjunto de figurinas cerámicas antropomorfas procedentes del Noroeste Argentino, específicamente de las provincias de Catamarca y La Rioja. Se propone una metodología que posibilite identificar en las representaciones corporales las formas de construir el cuerpo que circularon entre los habitantes del Noroeste Argentino entre los años 500 y $1500 \mathrm{AD}$. Se ha observado que los cuerpos presentados y representados a través de las figurinas antropomorfas muestran ciertas tendencias compartidas entre zonas de procedencia. Se presentan cuerpos plásticos, dinámicos y expresivos, cuerpos capaces de acercarse y alejarse de la figura humana, sin perder su "núcleo de humanidad".

Palabras clave: Figurinas cerámicas, Representación corporal, Cuerpos, Noroeste Argentino, Metodología.

This work presents the analysis of a set of anthropomorphic ceramic figurines from the Argentine Northwest, specifically from the provinces of Catamarca and La Rioja. A methodology is proposed in order to identify in the corporal representations the ways of constructing the body that circulated among the inhabitants of the Argentine Northwest between the years 500 and $1500 \mathrm{AD}$. It was observed that the bodies presented and represented through anthropomorphic figurines show certain tendencies that are shared by the different provenance areas. The bodies presented are plastic, dynamic and expressive, which can at the same move away from and get close to the human figure without losing their "core of humanity".

Keywords: Ceramic figurines, Corporal representation, Bodies, Argentine Northwest, Methodology.

\section{INTRODUCCIÓN}

En este trabajo se presenta el análisis de un conjunto de figurinas cerámicas antropomorfas provenientes del Noroeste Argentino, específicamente de distintos valles ubicados en las actuales provincias de Catamarca y La Rioja.

Dado que la mayoría de las piezas analizadas provienen de colecciones depositadas en museos, la información contextual con que contamos es muy limitada. Por sus características, como las técnicas y motivos decorativos, se las identificó como un representante más del fenómeno de estandarización del estilo Aguada, junto con las vasijas y objetos de bronce (González 1998, Raviña \& Callegari 1998). Estas características compartidas incluyen la forma de la cabeza y de los ojos, los peinados y tocados, adornos, pecheras y vestimentas, como las pieles de jaguar (González 1998; Raviña \& Callegari 1998; Gordillo 2009a, 2009b). En este sentido, muchas de estas piezas han sido adscritas al estilo Aguada y, de este modo, se las ubica temporalmente a mediados del primer milenio hasta mediados del segundo.

Las figurinas cerámicas antropomorfas son representaciones de la figura humana en tres dimensiones, las

\footnotetext{
A Laura Vilas, Instituto de las Culturas (IDECU), Universidad de Buenos Aires-CONICET, Facultad de Filosofía y Letras, Museo Etnográfico Juan B. Ambrosetti, Moreno 350 - C1091 CABA. Proyecto Arqueológico Chaschuil-Abaucán (Dirección N. Ratto). E-mail: lauravilas@yahoo.com.ar
} 
que generalmente no superan los $15 \mathrm{~cm}$ de altura y se han realizado con alto grado de pericia y detalle. Hasta el momento la mayoría de los trabajos las han abordado en relación con las técnicas de manufactura y características estilísticas. Esta propuesta intenta delinear una metodología que permita el análisis de esta materialidad, teniendo en cuenta sus características particulares, a fin de indagar acerca de los modos de construir estas representaciones y acercarnos a los posibles conceptos de cuerpo que circularon a través de ellas.

\section{EL CUERPO PRESENTADO Y REPRESENTADO. ANTECEDENTES}

Actualmente, la arqueología del cuerpo abandonó las posturas estáticas que abordaban las representaciones del cuerpo como simples señalamientos de categorías e identidades pre-existentes y estables. Los recientes trabajos se focalizan en concepciones del cuerpo y de sus representaciones como procesos y prácticas de construcción de identidad, planteando cuerpos vivenciados y sociales en constante construcción (Alberti 2001; Latour 2004; Bailey 2005; Joyce 2005, 2008, Sofaer 2006; Boric \& Robb 2008).

Se puede entonces establecer una estrecha vinculación entre la imagen corporal individual y la compartida socialmente por un grupo determinado, las cuales se encuentran en constante intercambio. Asimismo, y en este sentido, las imágenes corporales, los conceptos acerca del cuerpo y las corporalidades mismas pueden transformarse y utilizarse como campo de justificación de prácticas e ideologías, de prescripciones y de mandatos, $\mathrm{y}$ al mismo tiempo funcionar como lugares donde las identidades son formadas, definidas y discutidas, en ese constante devenir que caracteriza cualquier fenómeno social.

En esta línea, la cultura material que reproduce los cuerpos, como las figurinas antropomorfas, permite un acercamiento más a las relaciones entre cuerpos, personas, identidades y las organizaciones sociales que las produjeron.

El estudio de la figura humana para el Noroeste Argentino ha sido abordado por varios investigadores (González 1964, 1974, 1998; Sempé 1975; Kusch 1990; Aschero 2000; Bugliani 2004; Scattolin 2005; Alberti 2007; Gordillo 2009a; Gluzman 2010, entre otros). Estos trabajos se focalizaron en representaciones antropomorfas de dos dimensiones plasmadas en soportes cerámicos, metálicos o rupestres, y de tres dimensiones en el caso de vasijas donde la forma configura cuerpos humanos o cuando poseen apéndices antropomorfos. La mayoría de estos análisis apuntaron a caracterizar las particularidades de la representación de la figura humana a nivel de código compartido y lograron acercamientos a aspectos técnicos, estilísticos sociopolíticos y simbólicos.

Las representaciones del cuerpo humano en figurinas cerámicas constituyen reproducciones antropomorfas construidas en tres dimensiones y separadas de otros soportes. La particularidad de estas piezas radica en que, a diferencia de aquellas plasmadas en dos dimensiones en otros soportes, aquí el objeto mismo resulta la representación. Las figurinas configuran objetos en los que la representación del cuerpo en tres dimensiones es un fin en sí mismo.

Sobre estas piezas antropomorfas cerámicas actualmente se cuenta con registros, recopilaciones y descripciones (González 1998; Raviña \& Callegari 1998; Gordillo 2009a, 2009b). Aunque también se ha comenzado a incluirlas en estudios y sistematizarlas en contextos sociohistóricos particulares (Vilas 2013, Pastor 2016, Prieto 2017).

Muchas de estas piezas, o al menos la mayoría de las registradas, han sido adscritas al estilo Aguada (González 1998; Raviña \& Callegari 1998; Gordillo 2009a, 2009b) y por ello se las ubica temporalmente entre mediados del primer milenio y mediados del segundo.

Las figurinas de cerámica Aguada fueron descritas por González (1998), quien destacó la reproducción minuciosa de los detalles representados, como los peinados, los tocados y los variados cambios en la vestimenta. Este autor también se refirió a su rica variabilidad con relación a las diferentes formas de presentar los cuerpos. En este sentido, las personas del pasado a través de las figurinas antropomorfas han presentado los cuerpos con gran pericia técnica (González 1998, Raviña \& Callegari 1998), alto grado de detalle y amplia diversidad.

En cuanto a su distribución y procedencia, estas figurinas cerámicas se encontraron en distintos valles del NOA: Chaschuil, Fiambalá, Ambato, Andalgalá, Saujil y Calchaquí en Catamarca, y Antinaco, Famatina y Vinchina en La Rioja (Raviña \& Callegari 1998, Vilas 2013, Prieto 2017). Así también, se han reconocido en las sierras centrales de Córdoba y quebradas de Salta (González 1964, Raviña \& Callegari 1998, Pastor \& Tissera 2015). 
En su gran mayoría, las piezas han sido registradas en catálogos de colecciones depositadas en museos y en reportes de investigaciones arqueológicas conducidas en el Noroeste Argentino. En cuanto a sus contextos, no se cuenta con mucha información, pero aquellas provenientes de investigaciones arqueológicas han permitido ubicarlas en diversos contextos: funerario ( $\mathrm{La}$ Troya, Fiambalá, Catamarca), doméstico y basureros (La Rinconada, Valle de Ambato y Guanchín y Palo Blanco, Valle de Fiambalá, Catamarca) (Vilas 2013, Prieto 2017).

La habilidad de sus creadores para presentar los cuerpos en gran variabilidad, sumado a que en su gran mayoría provienen de colecciones depositadas en museos, demanda delinear una metodología que posibilite su abordaje teniendo en cuenta sus particularidades. El análisis debe poder guiarnos hacia conceptos estéticos compartidos o diferenciados, como así también a conceptos de cuerpo representados en toda su variedad e inestabilidad.

\section{DECONSTRUIR PARA CONSTRUIR. MATERIALES Y MÉTODOS}

\section{Materiales: qué figurinas analizar}

Las figurinas cerámicas antropomorfas resultan representaciones de la figura humana tridimensionales, modeladas y macizas. Se presentan en diversos tamaños, generalmente entre los $4 \mathrm{~cm}$ y los $15 \mathrm{~cm}$ de altura. Muestran un importante desarrollo técnico en relación con la reproducción del cuerpo humano, y como mencionábamos anteriormente, el objeto mismo es la representación (fig. 1). El cuerpo presentado se desprende y no participa en la configuración de otro objeto, como sí sucede cuando se configura en apéndice de vasijas o prestándose como forma contenedora, por ejemplo, en el caso de las vasijas Candelaria (Alberti 2007), las vasijas Santamarianas del formativo en el sur de los valles calchaquíes (Bugliani 2001) o las vasijas de Laguna Blanca en Catamarca (Scattolin \& Bugliani 2005). Las vasijas de este tipo se las consideran vasijas efigie, dado que resultan recipientes cuya forma participa en la propia figuración (Scattolin \& Bugliani 2005), sin embargo, no dejan de participar en la conformación de otro objeto, en este caso las vasijas.

El conjunto de figurinas antropomorfas analizadas proviene, por un lado, de intervenciones sistemáticas realizadas en el marco del Proyecto Arqueológico Chas-

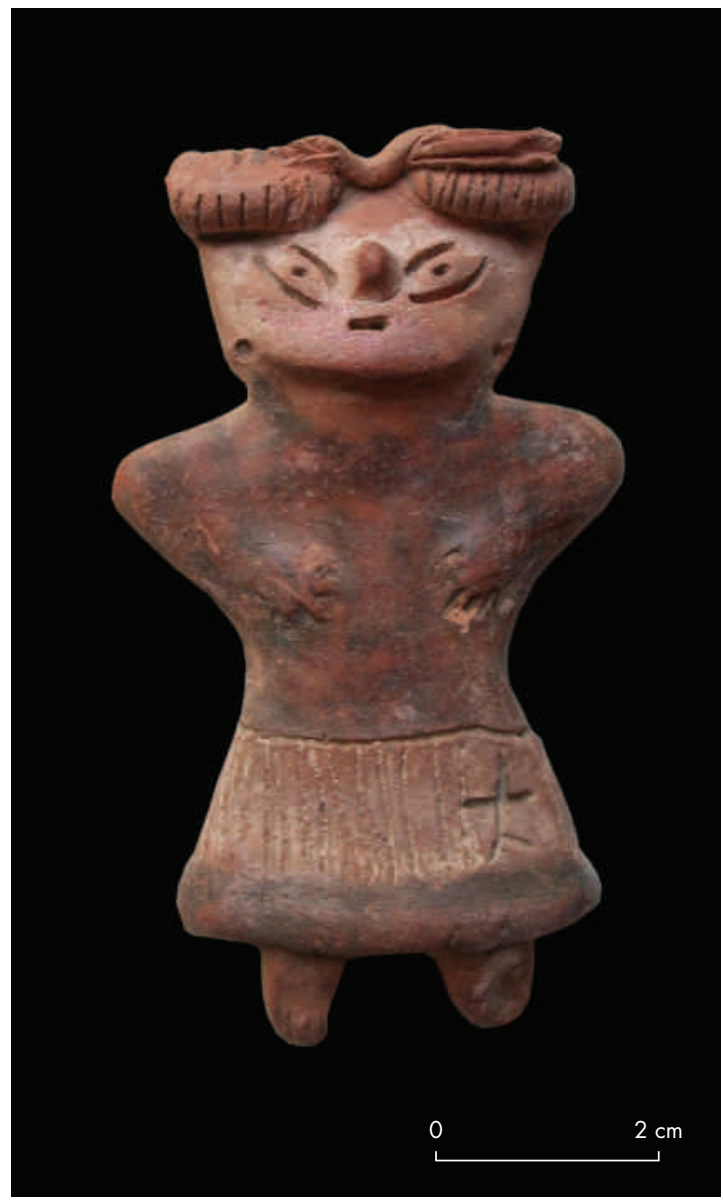

Figura 1. Figurina cerámica antropomorfa. Sin datos de procedencia (colección Museo Arqueológico Regional Inca Huasi de la Provincia de La Rioja). Figure 1. Anthropomorphic ceramic figurine. Provenance unknown. Inca Huasi Regional Archaeological Museum Collection, Province of La Rioja.

chuil-Abaucán, en el cual se inserta esta investigación, y por otro, del relevamiento de colecciones depositadas en el Museo Arqueológico Municipal Tulio Robaudi en Tinogasta y del Museo Arqueológico Municipal del Hombre de Fiambalá (Catamarca). Estas últimas son producto de intervenciones asistemáticas realizadas por pobladores locales en el área de La Troya, en el bolsón de Fiambalá (1500-2500 msnm) y alrededores. Finalmente, la muestra se completa con piezas depositadas en el Museo Etnográfico Juan B. Ambrosetti de la Ciudad Autónoma de Buenos Aires y en el Museo Arqueológico Regional Inca Huasi de la provincia de La Rioja, que resultan también de intervenciones asistemáticas en las provincias de Catamarca y La Rioja. 


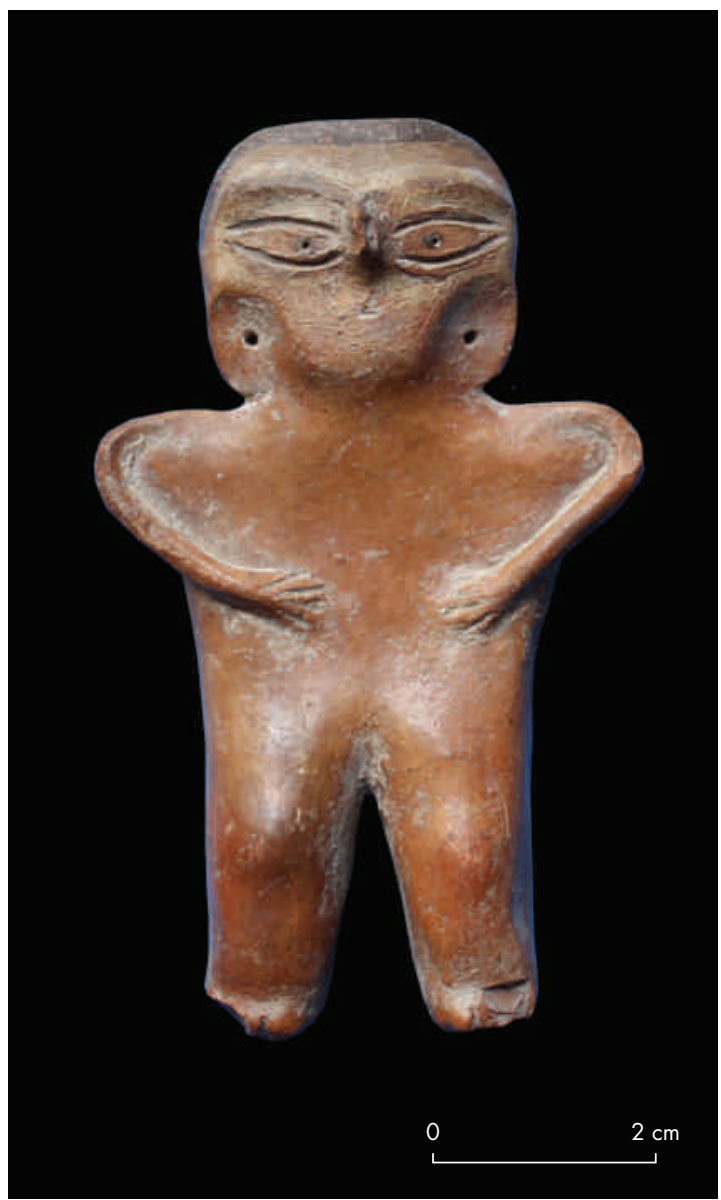

Figura 2. Figurina cerámica antropomorfa. Sin datos de procedencia (colección Museo Arqueológico Regional Inca Huasi de la Provincia de La Rioja). Figure 2. Anthropomorphic ceramic figurine. Provenance unknown. Inca Huasi Regional Archaeological Museum Collection, Province of La Rioja.

Al provenir en su mayoría de colecciones, no se cuenta con datos precisos acerca de sus contextos arqueológicos y muchas veces tampoco con relación a sus procedencias. Por otro lado, con respecto a la integridad de las piezas, en su mayoría se encuentran fragmentadas. Las que se conservan enteras representan una mínima proporción, de acuerdo con lo observado en la totalidad de las figuras relevadas. De un total de 528 piezas, solo 62 estaban enteras, lo que corresponde a un $11,75 \%$ de la muestra.

De un total de 528 figurinas relevadas, se ha seleccionado para este estudio una muestra de 105 piezas (enteras: $\mathrm{N}=54$, fragmentadas: $\mathrm{N}=51$ ). El criterio de selección fue el de incluir en el análisis aquellas figurinas que posean, al menos, cabeza y hombros (figs. 2-3).

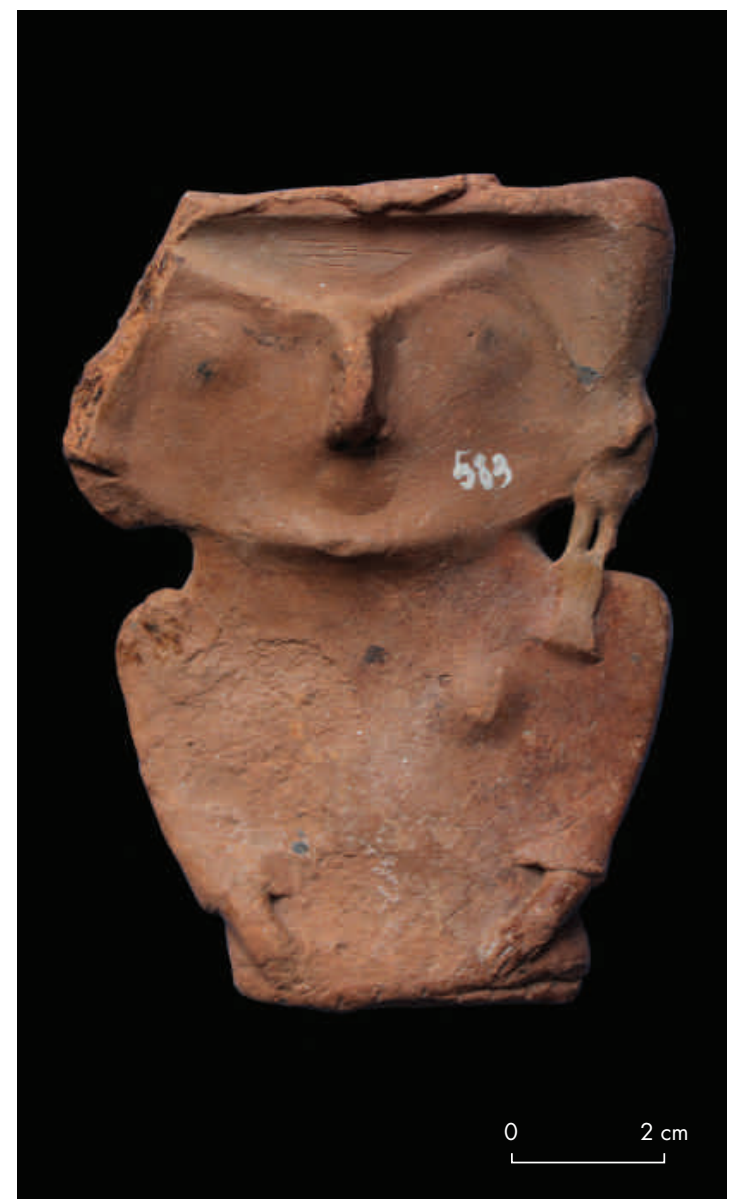

Figura 3. Figurina cerámica antropomorfa fragmentada. Procedente de San Blas, La Rioja (colección Museo Arqueológico Regional Inca Huasi de la Provincia de La Rioja). Figure 3: Fragmented anthropomorphic ceramic figurine. From San Blas, La Rioja. Inca Huasi Regional Archaeological Museum Collection, Province of La Rioja.

En cuanto a la procedencia de las piezas, se han agrupado aquellas provenientes de distintos valles que pertenecen actualmente a los territorios de la provincia de Catamarca, las de valles pertenecientes hoy al territorio de la provincia de La Rioja, y finalmente, aquellas de origen desconocido (tabla 1).

Los datos de procedencia de las figurinas cerámicas y su integridad nos dieron la primera información acerca de la representatividad del material para cada región, como así también información acerca de la proporción de piezas enteras y fragmentadas. De un total de 105 figurinas analizadas, 17 piezas proceden de diversos valles ubicados en la actual provincia de Catamarca, 36 piezas de valles de la actual provincia 
de La Rioja, y respecto de 52 piezas se desconocen sus datos de origen.

Dado que, en muchos de los casos la información obtenida a través de los catálogos de museos solo se refiere a la provincia de procedencia, y solo se cuenta con antecedentes detallados de pocos casos, se ha decidido agrupar aquellas piezas procedentes de los actuales territorios de las provincias de Catamarca, por un lado, y los de La Rioja, por otro. Se requeriría de mayores datos acerca de las localizaciones geográficas específicas de cada pieza para poder realizar un análisis más detallado por ecozonas o valles particulares.

\section{METODOLOGÍA}

La propuesta metodológica aborda el estudio de las figurinas teniendo en cuenta su distribución y el análisis de sus atributos, el cual incluye dos dimensiones: variables cualitativas y cuantitativas. El análisis de los atributos se orienta, por un lado, a la identificación de variables cualitativas, para ello se determinaron ocho variables (tabla 2). Estas variables fueron consignadas por presencia o ausencia, a partir de lo cual se calcularon frecuencias totales y frecuencias por procedencia. Por otro lado, el análisis de los atributos también se orientó a la identificación de variables cuantitavas. Para ello se
Tabla 1. Total de figurinas relevadas y muestra seleccionada. Table 1. Total of surveyed figurines and sample selected.

\begin{tabular}{|c|c|c|c|}
\hline \multicolumn{4}{|c|}{ TOTAL FIGURINAS RELEVADAS } \\
\hline PROCEDENCIA & TOTAL & ENTERAS & FRAGMENTADAS \\
\hline Catamarca & 149 & 17 & 132 \\
\hline La Rioja & 163 & 17 & 146 \\
\hline Salta & 9 & 1 & 8 \\
\hline Tucumán & 3 & 0 & 3 \\
\hline Córdoba & 4 & 0 & 4 \\
\hline Desconocida & 200 & 27 & 173 \\
\hline Total & 528 & 62 & 466 \\
\hline \multicolumn{4}{|c|}{ TOTAL FIGURINAS ANALIZADAS } \\
\hline Catamarca & 17 & 10 & 7 \\
\hline La Rioja & 36 & 17 & 19 \\
\hline Desconocida & 52 & 27 & 25 \\
\hline Total & 105 & 54 & 51 \\
\hline
\end{tabular}

Tabla 2. Descripción de las variables cualitativas consignadas. Table 2. Description of the qualitative variables recorded.

\section{VARIABLES CUALITATIVAS}

\begin{tabular}{|c|c|}
\hline Partes del cuerpo presentes & $\begin{array}{l}\text { Cabeza }+ \text { torso, cabeza }+ \text { torso }+ \text { brazos, cabeza }+ \text { torso }+ \text { piernas, cabeza }+ \text { torso } \\
+ \text { brazos }+ \text { piernas }\end{array}$ \\
\hline \multirow[t]{2}{*}{ Tratamientos plásticos } & Técnica de modelado: bulto o plancha \\
\hline & Tratamiento de superficie: alisado y engobe \\
\hline Recursos plásticos & Modelado, perforado, inciso, pastillaje y pintura \\
\hline Ornamentación & Tocado o peinado \\
\hline Adornos & Vestimenta, collares, pendientes, brazaletes \\
\hline Gesto facial & Ojos cerrados, boca abierta o cocida \\
\hline Actitud & $\begin{array}{l}\text { Sin movimiento, movimiento de brazos, movimiento de piernas y movimientos } \\
\text { de brazos y piernas }\end{array}$ \\
\hline Sexo & Presencia de genitales femeninos o masculinos, o sin marca \\
\hline
\end{tabular}


establecieron medidas y proporciones corporales en índices, o sea, relaciones entre las medidas corporales contempladas (tabla 3).

\section{Un cuerpo y varios cuerpos. Análisis y resultados}

\section{Variables cualitativas}

En cuanto a las partes del cuerpo seleccionadas para configurar cada cuerpo, del análisis de frecuencias (tabla 4) se obtiene que, en la mayoría de las figurinas, la intención fue presentar la totalidad del cuerpo, o sea presencia de cabeza, torso, brazos y piernas. Del total de figurinas analizadas (N:105), la mayoría (N:55) muestra esta configuración. No obstante, también se presentan cuerpos que poseen cabeza, torso y brazos, con ausencia de piernas (N:25), cuerpos con cabeza, torso y piernas y ausencia de brazos (N:12) y cuerpos configurados solo con cabeza y torso (N:13).

El análisis de los tratamientos plásticos (tabla 5), las técnicas de modelado y los tratamientos de superficie demuestran que se ha utilizado con mayor frecuencia la técnica de modelado en bulto (N:70) y, en menor medida, la técnica en plancha (Raviña \& Callegari 1998) (N:35). En cuanto a los tratamientos de superficie, se ha utilizado en su mayoría las técnicas de alisado y engobe (N:80) y, en menor medida, solo el alisado ( $\mathrm{N}: 25)$. El engobe se presenta en distintas tonalidades de rojo.

Los recursos plásticos seleccionados para construir los cuerpos (tabla 6) presentan distintas frecuencias, indicando que el modelado es el más frecuentemente empleado ( $\mathrm{N}: 105)$ junto con el inciso $(\mathrm{N}: 104)$ y el pastillaje (N:83), mientras que el perforado (N:26) y la pintura (N:7) fueron utilizados de manera más limitada.

El modelado fue empleado para dar forma a las figuras a partir del bollo o la lámina. El inciso se utilizó para terminar de definir formas, fijar detalles de los rostros, torso y extremidades, sumar detalles anatómicos, como así también para concretar los peinados, la ornamentación y adornos. La técnica de pastillaje sirvió, sobre todo, para incluir detalles en los cuerpos como el peinado, adornos y vestimentas. El perforado fue poco utilizado, pero cuando aparece, define orificios en orejas generalmente. La pintura se implementó para dar color en detalles, como en los peinados, adornos y ornamentación, ya sea dándoles color o dibujándolos sobre los cuerpos, de este modo también se usó para
Tabla 3. Descripción de variables cuantitativas consignadas. Table 3. Description of quantitative variables recorded.

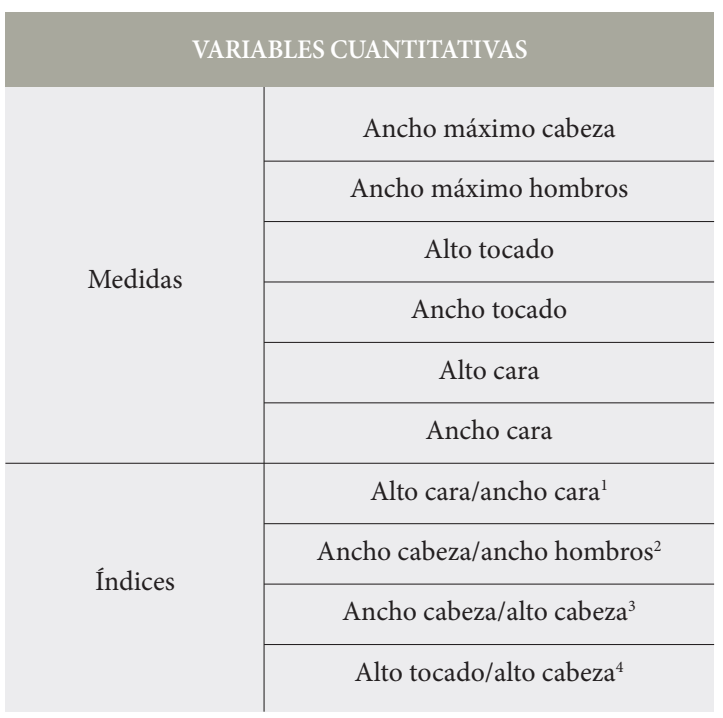

Tabla 4. Partes del cuerpo seleccionadas para configurar el cuerpo. Table 4. Body parts selected to shape the body.

\begin{tabular}{c|c|c} 
PARTES DEL CUERPO & FRECUENCIA & $\%$ \\
\hline Cabeza + torso & 13 & 12,4 \\
\hline Cabeza + torso + brazos & 25 & 23,8 \\
\hline Cabeza + torso + piernas & 12 & 11,4 \\
\hline Cabeza + torso + brazos + piernas & 55 & 52,4 \\
\hline Total & 105 & 100
\end{tabular}

Tabla 5. Tratamientos plásticos. Table 5. Plastic treatments.

\begin{tabular}{|c|c|c|}
\hline \multicolumn{2}{|c|}{ TRATAMIENTOS PLÁSTICOS } \\
\hline TÉCNICA DE MODELADO & FRECUENCIA & $\%$ \\
\hline En bulto & 35 & 33,3 \\
\hline En plancha & 70 & 66,7 \\
\hline Total & 105 & 100 \\
\hline TRATAMIENTO DE SUPERFICIE & FRECUENCIA & $\%$ \\
\hline En bulto & 35 & 33,3 \\
\hline En plancha & 70 & 66,7 \\
\hline Total & 105 & 100 \\
\hline
\end{tabular}


Tabla 6. Recursos plásticos. Table 6. Plastic resources.

\begin{tabular}{|c|c|c|}
\hline \multicolumn{3}{|c|}{ TRATAMIENTOS PLÁSTICOS } \\
\hline MODELADO & FRECUENCIA & $\%$ \\
\hline Presencia & 105 & 100 \\
\hline PERFORADO & FRECUENCIA & $\%$ \\
\hline Ausencia & 79 & 75,2 \\
\hline Presencia & 26 & 24,8 \\
\hline Total & 105 & 100 \\
\hline INCISO & FRECUENCIA & $\%$ \\
\hline Ausencia & 1 & 1 \\
\hline Presencia & 104 & 99 \\
\hline Total & 105 & 100 \\
\hline PASTILLAJE & FRECUENCIA & $\%$ \\
\hline Ausencia & 22 & 21 \\
\hline Presencia & 83 & 79 \\
\hline Total & 105 & 100 \\
\hline PINTURA & FRECUENCIA & $\%$ \\
\hline Ausencia & 98 & 93,3 \\
\hline Presencia & 7 & 6,7 \\
\hline Total & 105 & 100 \\
\hline
\end{tabular}

realizar motivos sobre las caras como pintura facial. La pintura utilizada en su mayoría fue de colores negro y rojo.

Hay atributos asociados a los cuerpos (tabla 7), como la ornamentación, aquí considerada en la presencia de tocados y peinados que se hacen presentes en la mayoría de las figurinas (65:105). Los tocados aparecen como detalles sobre las cabezas, en formas de vinchas, o tipo sombreros, como así también acompañando los elaborados peinados. Hay casos donde una especie de sombrero, dados sus motivos, parecería representar estar realizado en piel de jaguar. Aparece una gran variabilidad de peinados, muchos de ellos formados por trenzas, rodetes, elaborados recogidos o combinación de estos tres.

En este sentido, los adornos también se suman a los cuerpos, pero en una frecuencia menor (22:105). Estos se representan mediante la vestimenta, collares,
Tabla 7. Atributos asociados al cuerpo. Table 7. Attributes associated to the body.

\begin{tabular}{|c|c|c|}
\hline \multicolumn{3}{|c|}{ ATRIBUTOS ASOCIADOS AL CUERPO } \\
\hline ORNAMENTACIÓN & FRECUENCIA & $\%$ \\
\hline Ausencia & 40 & 38,1 \\
\hline Presencia & 65 & 61,9 \\
\hline Total & 105 & 100 \\
\hline ADORNOS & FRECUENCIA & $\%$ \\
\hline Ausencia & 83 & 79 \\
\hline Presencia & 22 & 21 \\
\hline Total & 105 & 100 \\
\hline GESTO FACIAL & FRECUENCIA & $\%$ \\
\hline Ausencia & 47 & 44,8 \\
\hline Presencia & 58 & 55,2 \\
\hline Total & 105 & 100,0 \\
\hline SEXO & FRECUENCIA & $\%$ \\
\hline Sin marca & 84 & 80 \\
\hline Masculino & 3 & 2,9 \\
\hline Femenino & 18 & 17,1 \\
\hline Total & 105 & 100 \\
\hline
\end{tabular}

pendientes y brazaletes. En la ya citada figura 1 se puede observar la presencia de ornamentación a través de un peinado y de adornos mediante la vestimenta. La pieza de dicha figura posee un elaborado peinado a modo de rodetines en dos partes, el cual fue definido a partir del modelado, el inciso y adherido mediante pastillaje. Además, tiene collares y adornos corporales dibujados sobre el torso mediante pintura negra. A través de la técnica del inciso sobre las orejas se incluyó la apariencia de pendientes. También presenta un tipo de falda, conformada y adornada con motivos realizados a través del inciso.

Entre los atributos asociados al cuerpo se consignó, a su vez, la presencia de gesto facial, representado por los ojos cerrados, la boca abierta o cocida. Este atributo se observa también en la mayoría de las figurinas (58:105). La boca cocida, vista a través de labios atravesados por 
Tabla 8. Variable actitud. Table 8. Attitude variable.

\begin{tabular}{c|c|c|c|c|c} 
& SIN MOVIMIENTO & $\begin{array}{c}\text { MOVIMIENTO } \\
\text { DE BRAZOS }\end{array}$ & $\begin{array}{c}\text { MOVIMIENTO } \\
\text { DE PIERNAS }\end{array}$ & $\begin{array}{c}\text { MOVIMIENTO DE } \\
\text { BRAZOS Y PIERNAS }\end{array}$ & ÁREA \\
\hline Catamarca & 8 & 2 & 0 & 7 & 17 \\
\hline La Rioja & 10 & 17 & 4 & 5 & 36 \\
\hline Desconocida & 24 & 19 & 1 & 8 & 52 \\
\hline Total & 42 & 38 & 5 & 20 & 105
\end{tabular}

líneas verticales (Costas 2017), mostraría una intención de representar una práctica en el rostro, de este modo se lo considera dentro del atributo gesto facial. Verano (2003) señala que, entre las prácticas relacionadas con la momificación de cabezas en Perú, los labios y a veces los párpados eran cosidos con espinas de algarrobo o cactus. El gesto facial más representado fue el de la boca abierta, luego los ojos cerrados y en menor medida la boca cosida.

La variable actitud asociada al cuerpo se identificó a través de la presencia de alguna intención de movimiento (tabla 8) en relación con la posición de brazos y piernas: sin movimiento, movimiento de brazos (figs. 4-5), movimiento de piernas y movimientos de brazos y piernas conjuntamente (fig. 6). En la mayoría de las figurinas se observa algún tipo de actitud (N:63), por ejemplo: movimientos de brazos (N:38), en una mínima representación solo movimiento de piernas (N:5), y aquellas figurinas que combinaron ambos movimientos resultaron una minoría ( $\mathrm{N}: 20)$.

Este atributo se registró además respecto de las procedencias, obteniéndose una relación estadísticamente significativa entre la variable actitud y la zona de procedencia. ${ }^{5}$ Se observó, entonces, que las piezas de la actual zona de Catamarca presentan una tendencia a los movimientos de brazos y piernas al mismo tiempo, mientras que las de las zonas de la actual La Rioja solo de brazos y, aquellas sin datos de procedencia, presentan una tendencia a no imprimir movimiento en los cuerpos.

En cuanto a la intención de mostrar alguna señal de sexo en los cuerpos (fig. 7) a través de genitales masculinos o femeninos o pechos, la mayoría de los cuerpos no los presentan (84:105), sin embargo, en aquellas que sí los hay (21:105), la mayoría resultaron genitales femeninos y pechos (18:21:105).

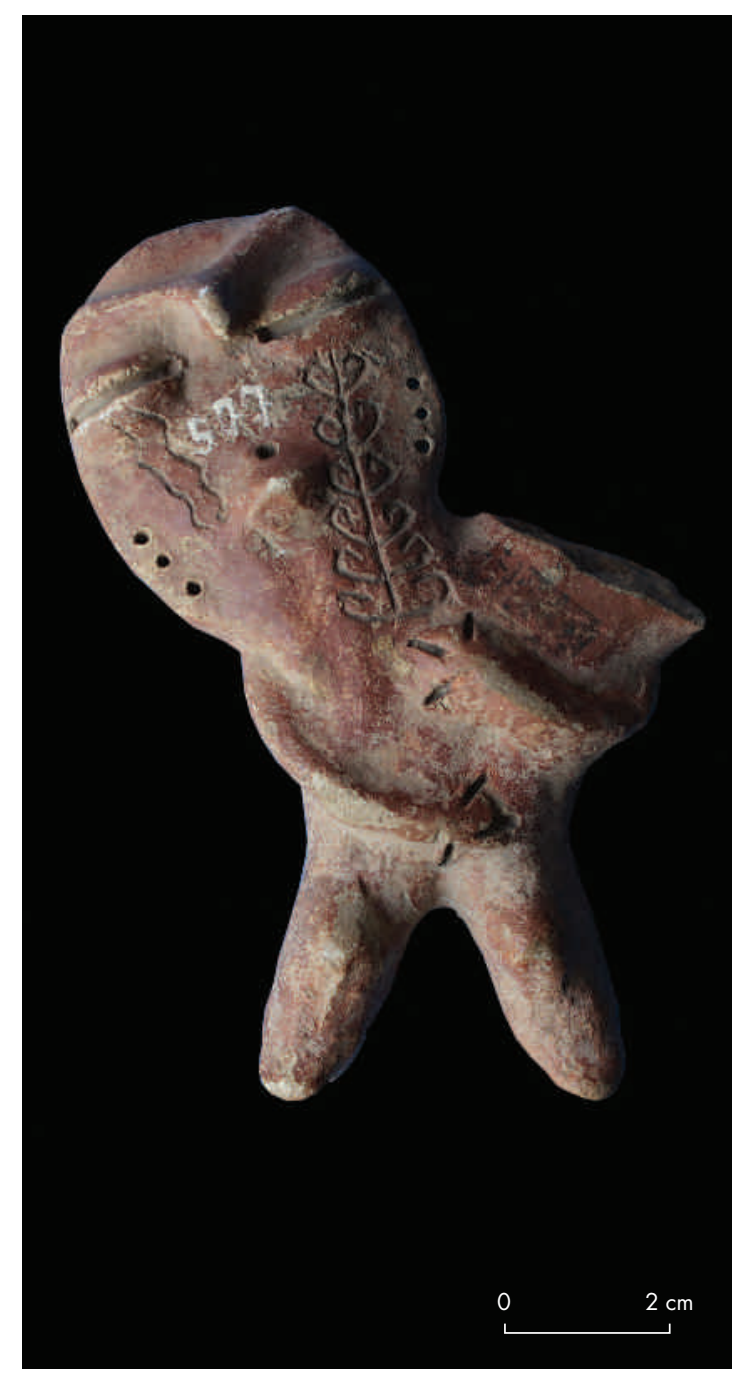

Figura 4. Figurina cerámica antropomorfa fragmentada. Procedente de Vinchina, La Rioja (colección Museo Arqueológico Regional Inca Huasi de la Provincia de La Rioja). Figure 4. Fragmented anthropomorphic ceramic figurine. From Vinchina, La Rioja. Inca Huasi Regional Archaeological Museum Collection, Province of La Rioja. 


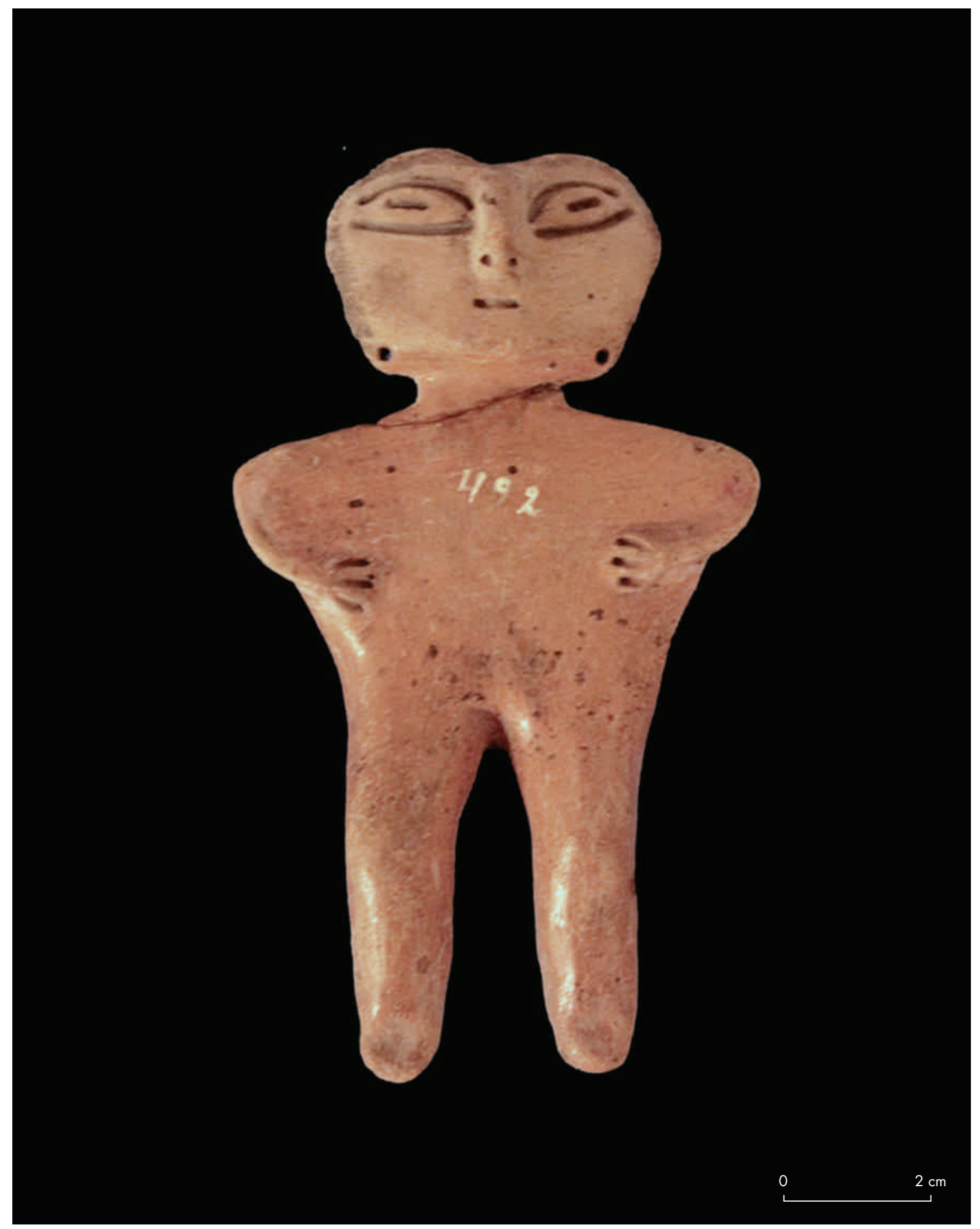

Figura 5. Figurina cerámica antropomorfa. Procedente de San Blas de los Sauces, La Rioja (colección Museo Arqueológico Regional Inca Huasi de la Provincia de La Rioja). Figure 5. Anthropomorphic ceramic figurine. From San Blas de los Sauces, La Rioja. Inca Huasi Regional Archaeological Museum Collection, Province of La Rioja. 


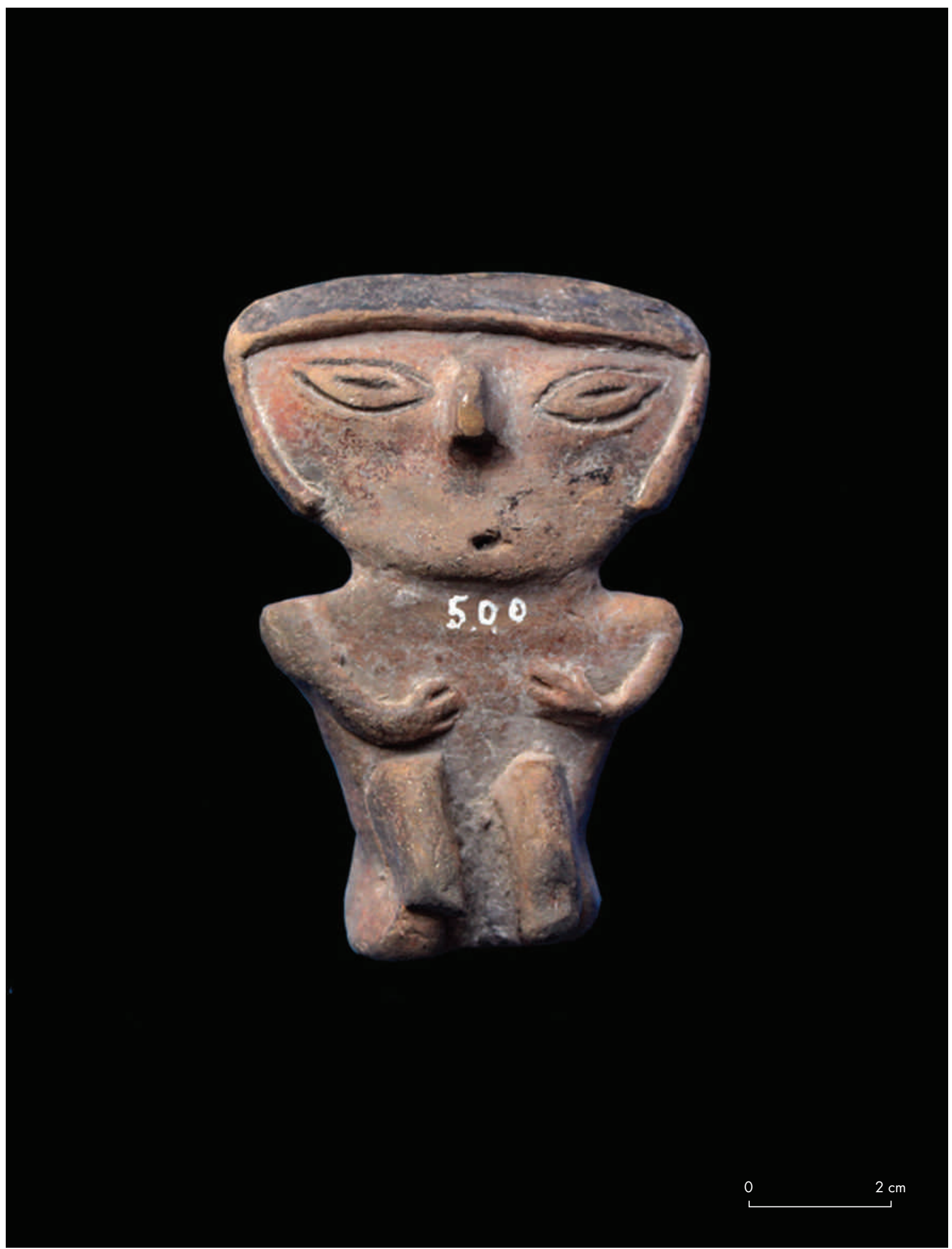

Figura 6. Figurina cerámica antropomorfa. Procedente de Huillapima, Capayán, Catamarca (colección Museo Arqueológico Regional Inca Huasi de la Provincia de La Rioja). Figure 6. Anthropomorphic ceramic figurine. From Huillapima, Capayán, Catamarca. Inca Huasi Regional Archaeological Museum Collection, Province of La Rioja. 


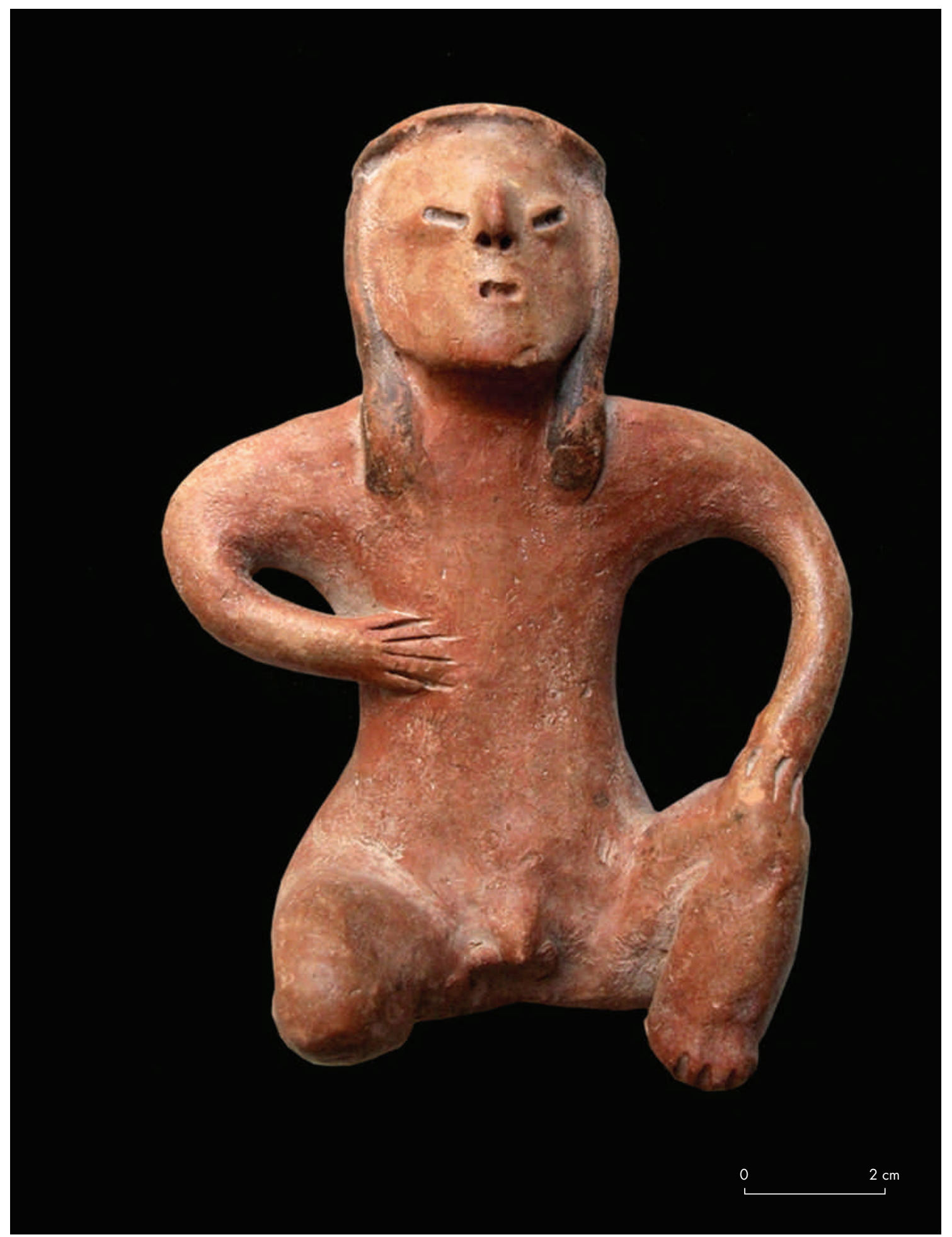

Figura 7. Figurina cerámica antropomorfa. Procedente de San Blas de los Sauces, La Rioja (colección Museo Arqueológico Regional Inca Huasi de la Provincia de La Rioja). Figure 7. Anthropomorphic ceramic figurine. From San Blas de los Sauces, La Rioja. Inca Huasi Regional Archaeological Museum Collection, Province of La Rioja. 


\section{VARIABLES CUANTITATIVAS}

Las variables cuantitativas se analizaron a través de medidas corporales, relacionándolas entre sí a través de índices que permitieron observar las proporciones empleadas para configurar el cuerpo en cada figurina.

El primer índice analizado fue el que relaciona el alto de la cara con su ancho (fig. 8). Aquí, los resultados indicaron que, en la mayoría de los casos, se presenta una cara más ancha que alta, sin diferencias significativas entre zonas de procedencia.

El segundo índice considerado fue el del ancho de cabeza con relación al ancho de hombros (fig. 9). Respecto de las zonas de procedencia, la mayoría de las figurinas de los valles de la actual Catamarca (N:17) poseen cabezas más anchas que sus hombros (fig. 10). Las de los valles de La Rioja (N:36) presentan valores distribuidos equilibradamente entre aquellas con cabezas más anchas que los hombros y otras con hombros más anchos que la cabeza. Mientras que las de procedencia desconocida (N:52) se ubicaron dentro de los valores que indican hombros más anchos que cabezas.

El tercer índice considerado fue aquel que relaciona el ancho y el alto de la cabeza (fig. 11). En este caso, no hubo diferencias significativas entre zonas de procedencia, y en la mayoría de las figurinas se observan cabezas más anchas que largas (fig. 12).

El último índice analizado relaciona el alto del tocado con el alto de la cabeza (fig. 13). En este caso se analizaron solo aquellas figurinas con presencia de tocado (N:46). Este índice muestra cuánto se destaca el tamaño del tocado con relación a la cabeza. Los resultados señalan que no habría diferencias entre zonas de procedencia respecto de esta relación, observándose una tendencia general a que el tocado represente un tercio del total de la cabeza, por lo tanto, se destaca (figs. 1 y 14).

\section{ÍNDICE ALTO CARA/ANCHO CARA}

Catamarca (17:105)

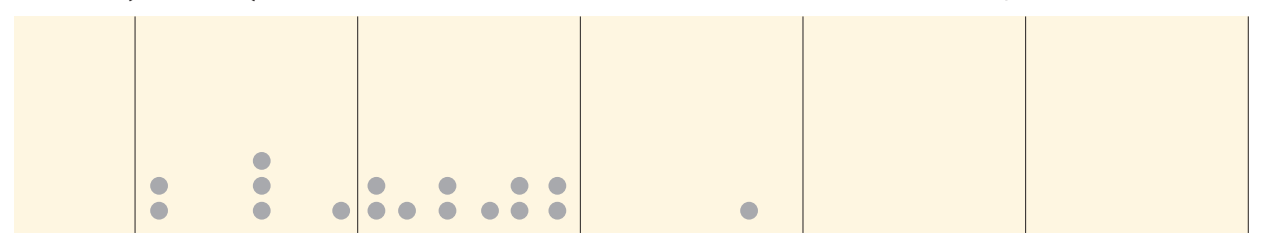

La Rioja (36: 105)

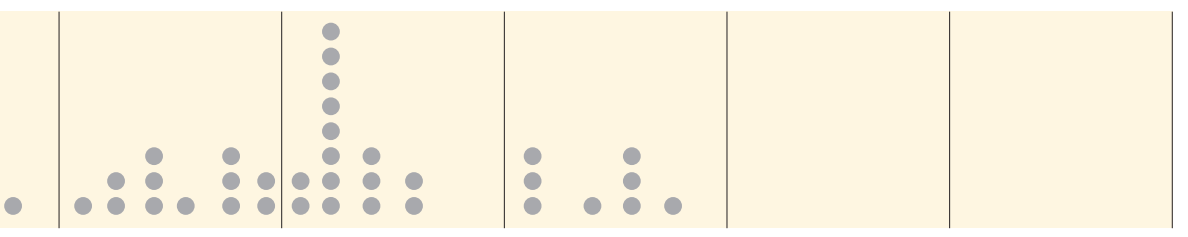

Desconocido (52:105)

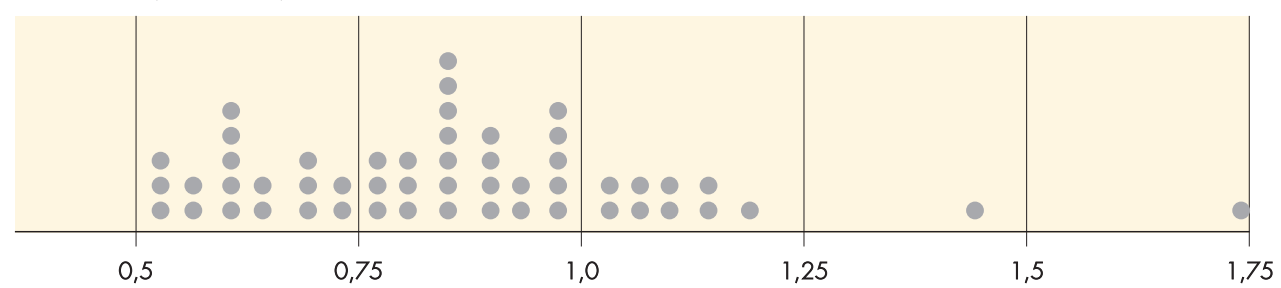

Figura 8. Resultados obtenidos a través del índice alto cara/ancho cara. Figure 8. Results obtained through the face height/face width index. 


\section{ÍNDICE ANCHO CABEZA/ANCHO HOMBROS}

\section{Catamarca (17:105)}

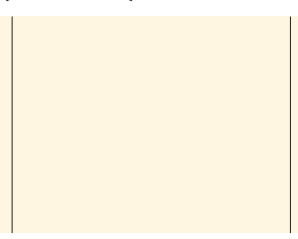

- Casos con un valor de índice similar apilados verticalmente

La Rioja (36:105)

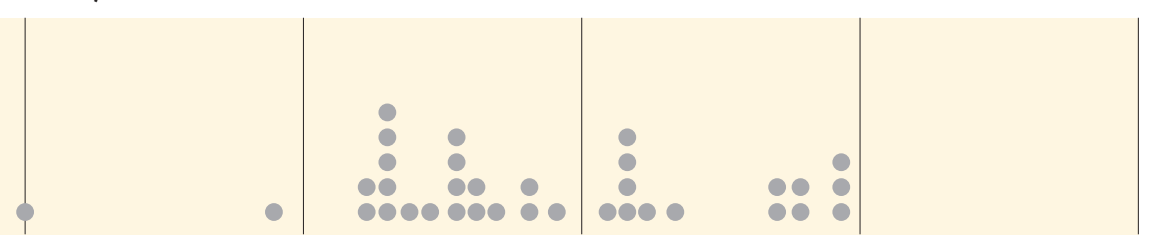

Desconocido (52:105)

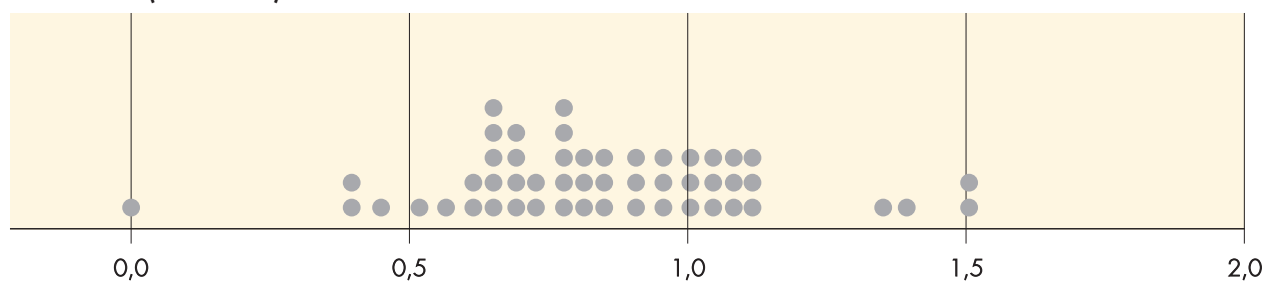

Figura 9. Resultados obtenidos a través del índice ancho cabeza/ancho hombros. Figure 9. Results obtained through the head width/ shoulder width index.

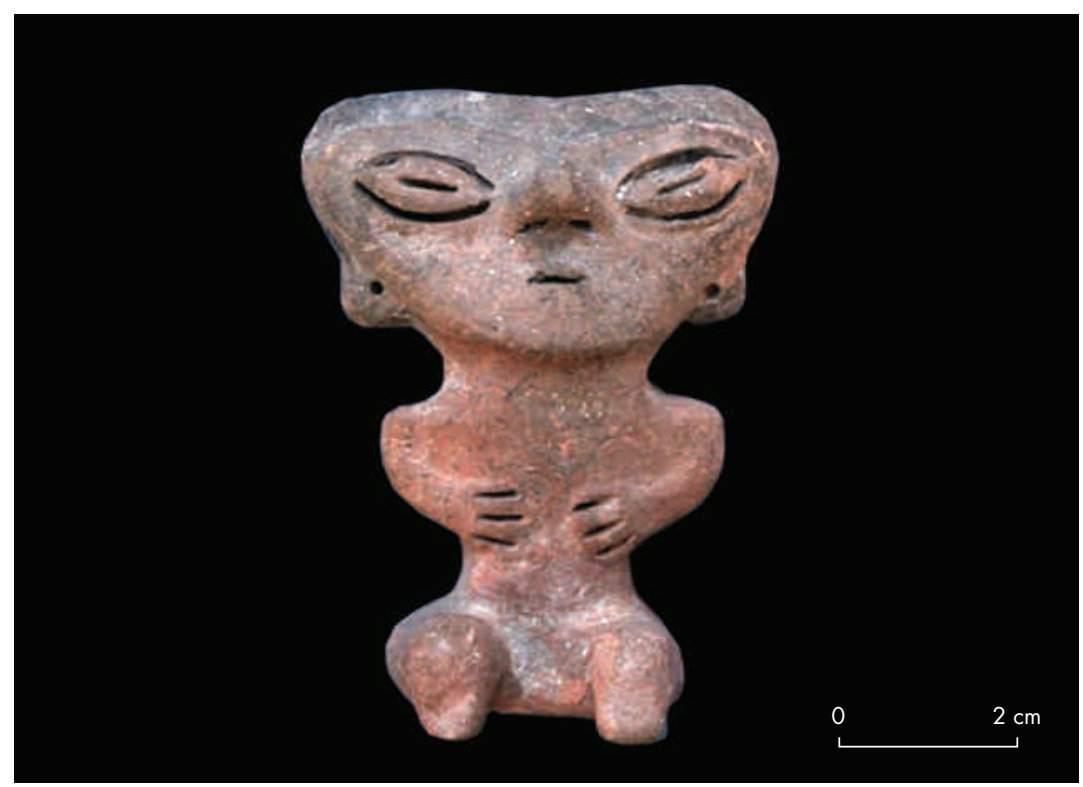

Figura 10. Figurina cerámica antropomorfa. Procedente de Huillapima, Capayán, Catamarca (Colección Museo Arqueológico Regional Inca Huasi de la Provincia de La Rioja). Figure 10. Anthropomorphic ceramic figurine. From Huillapima, Capayán, Catamarca. Inca Huasi Regional Archaeological Museum Collection, Province of La Rioja. 


\section{ÍNDICE ANCHO CABEZA/ALTO CABEZA}

\section{Catamarca (17:105)}

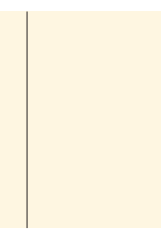

La Rioja (36:105)

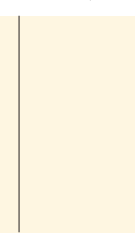

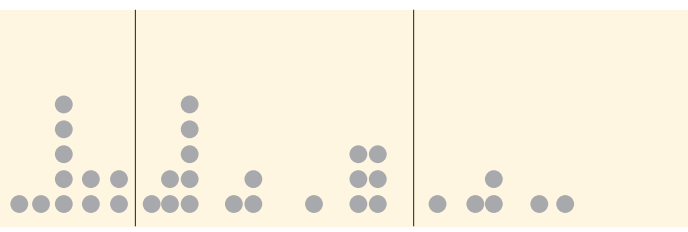

- Casos con un valor de índice similar apilados verticalmente

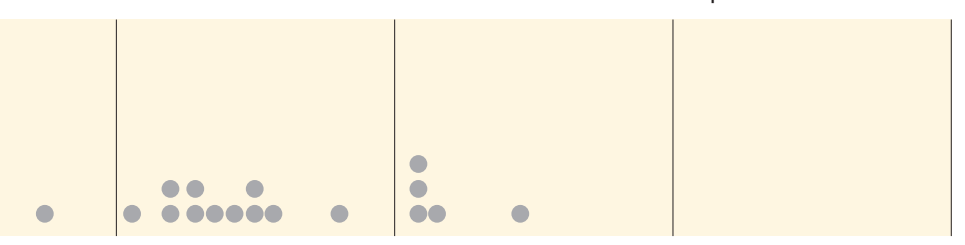

Desconocido (52:105)

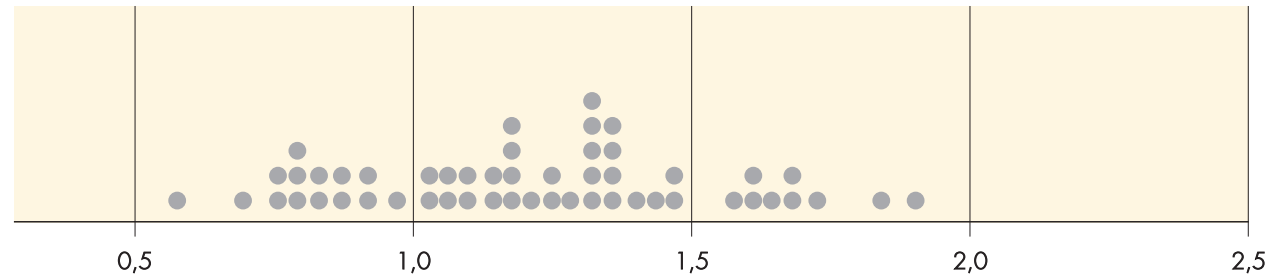

Figura 11. Resultados obtenidos a través del índice ancho cabeza/alto cabeza. Figure 11. Results obtained through the head width/head height index.

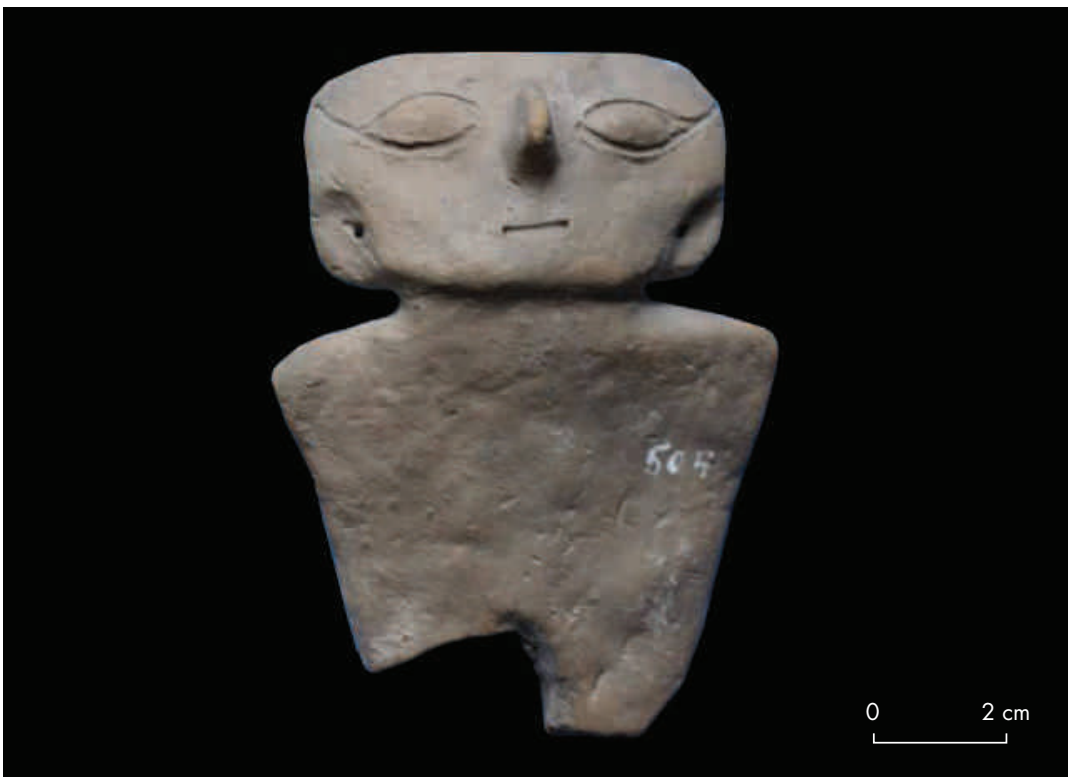

Figura 12. Figurina cerámica antropomorfa fragmentada. Procedente de Sanagasta, La Rioja (colección Museo Arqueológico Regional Inca Huasi de la Provincia de La Rioja). Figure 12. Fragmented anthropomorphic ceramic figurine. From Sanagasta, La Rioja. Inca Huasi Regional Archaeological Museum Collection, Province of La Rioja. 


\section{ÍNDICE ALTO TOCADO/ALTO CABEZA}

Catamarca (17:17:105)

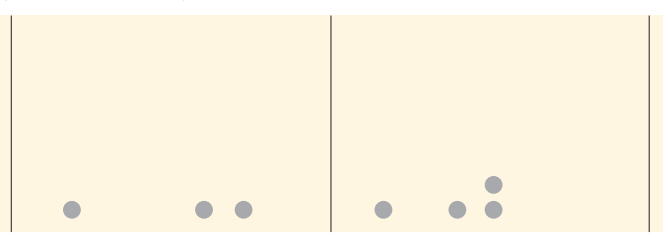

- Casos con un valor de índice similar apilados verticalmente

La Rioja (18:36:105)

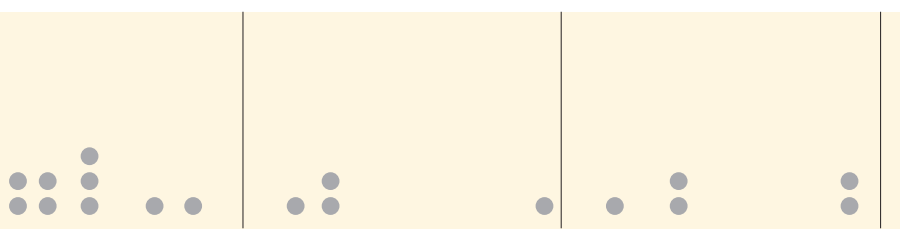

Desconocido (22:52:105)

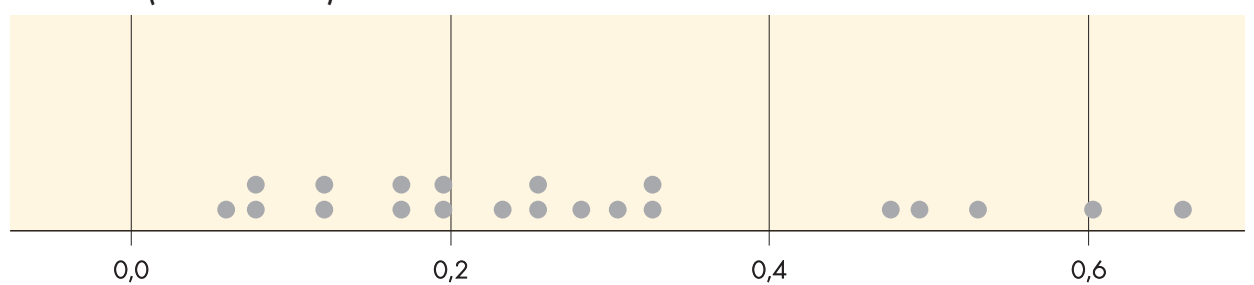

Figura 13. Resultados obtenidos a través del índice alto tocado/alto cabeza. Figure 13. Results obtained through the headdress height/ head height index.

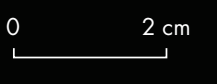

Figura 14. Figurina cerámica antropomorfa. Sin datos de procedencia (colección Museo Arqueológico Regional Inca Huasi de la Provincia de La Rioja). Figure 14. Anthropomorphic ceramic figurine. Provenance unknown. Inca Huasi Regional Archaeological Museum Collection, Province of La Rioja. 


\section{UN NÚCLEO Y VARIOS CUERPOS. DISCUSIÓN}

De los resultados obtenidos se pudieron observar ciertas tendencias en cuanto a las técnicas y atributos seleccionados para configurar y presentar los cuerpos antropomorfos en las figurinas analizadas.

En cuanto a la presentación del cuerpo, hay una tendencia a mostrar la figura humana completa, sin embargo, se encuentra cierta variabilidad. Si bien, hay cuerpos que se acercan a la figura humana con sus cuatro miembros, también se advierten formas que se alejan, delineando cuerpos sin miembros superiores o inferiores. Habría un núcleo más estable representado por el conjunto de cabeza y tronco, este núcleo parecería conformar la unidad mínima para configurar la "humanidad" de estos cuerpos. En este sentido, se podría pensar en cuerpos que permiten la flexibilidad de sus formas a partir de este núcleo, y aceptan variaciones que los alejan de la figura humana real; se puede ir y volver a ella, con la plasticidad que permiten la arcilla y los conceptos de cuerpo.

Con relación a los tratamientos plásticos seleccionados (técnica de modelado y acabado de superficie) se encontraron tendencias compartidas. En la mayoría de los casos se modeló a partir de la plancha y se utilizó el alisado y engobe. Lo mismo sucede con los recursos plásticos: el modelado, inciso y pastillaje se encuentran en frecuencias altas, mientras que el perforado y la pintura parecerían ser aplicadas solo en ciertos casos y no resultan técnicas frecuentemente empleadas.

Otra variable considerada fue aquella que consignaba atributos asociados a los cuerpos, como la ornamentación (tocado y peinado) y los adornos (vestimenta, collares, pendientes y brazaletes). La mayoría de los cuerpos de la muestra presentó algún tipo de ornamentación en la cabeza, mediante elaborados tocados y peinados. Sin embargo, los adornos resultan un recurso poco frecuente, seleccionado en ciertos casos particulares, para destacar cuerpos específicos. No se encontró diferencia entre las zonas de procedencia en relación con la distribución de estos atributos. En todas las zonas se configuraron cuerpos expresivos, donde la cabeza resulta la protagonista y el rasgo a destacar.

El dinamismo en la figura humana se puede imprimir a partir del movimiento de los miembros superiores e inferiores y de los gestos faciales. Este último, considerado aquí a través de ojos cerrados, boca abierta, o cocida, se hizo presente en más de la mitad de la muestra, sin diferencia de frecuencia entre zonas de procedencia. Nuevamente la cabeza, en este caso la cara, es protagonista de la expresión de estos cuerpos.

Hasta aquí, si bien hay cierto grado de variabilidad, no se encontraron diferencias significativas en el modo de construir las figurinas procedentes de los distintos valles que hoy pertenecen a las provincias de Catamarca y La Rioja. Aquellas figurinas sin datos de origen se incluyen en esta tendencia. Las formas de hacer los cuerpos, en cuanto a las técnicas parecerían ser compartidas entre valles.

Por otro lado, el dinamismo también fue impreso a través del movimiento de los miembros superiores e inferiores, observado en la mayoría de las figurinas. Gran parte asignado a los brazos, una mínima solo de piernas, y una minoría combinaron movimientos de brazos y piernas al mismo tiempo. En este sentido, el dinamismo de los cuerpos estaría más asociado al movimiento de los brazos.

En relación con las procedencias, se pudo observar que, en las figurinas de valles catamarquinos se presenta una tendencia a los movimientos de brazos y piernas al mismo tiempo, mientras que aquellas de valles de La Rioja solo de brazos. En las figurinas sin datos, en la mayoría no se atisban intenciones de mostrar dinamismo en los cuerpos a través de sus miembros. Esto no se puede considerar significativo en cuanto a indicios de su procedencia, pero sí con relación a la variabilidad en las formas de presentar los cuerpos. Por otro lado, aquí comienzan a aparecer las diferencias en las formas de configurar los cuerpos entre zonas de procedencias. Aquellas procedentes de valles de la actual Catamarca presentan una tendencia mayor a configurar el movimiento a través de todo el cuerpo.

Otra forma de construir un cuerpo se refleja en la intención de mostrar alguna marca de sexo, en este sentido una minoría mostró genitales, la mayoría femeninos. Aquí habría que indagar las posibles diferencias entre las concepciones de cuerpos femeninos y masculinos en trabajos futuros, en los que se puedan considerar más variables y profundizar en la temática de género sumando otras líneas de evidencia.

A partir de los resultados obtenidos del análisis de las variables cuantitativas se advierten también ciertas tendencias en cuanto a la configuración de los cuerpos. Los índices considerados permiten relacionar distintas medidas y proporciones corporales. 
La primera tendencia se vincula con la forma de la cara que, en la mayoría de los casos, son más anchas que altas, sin diferencias significativas entre zonas de procedencias. En casi todos los casos de figurinas procedentes de los valles de Catamarca se advierte esta tendencia. Las procedentes de valles de la actual Rioja, si bien acompañaron esta tendencia, hay algunos casos donde la cara resultó más alta que ancha. Las figurinas sin datos de procedencia acompañan la variabilidad de aquellas de los valles de La Rioja. Otro índice considerado fue el que relaciona el ancho y el alto de la cabeza. En este caso, nuevamente no se presentaron diferencias significativas entre procedencias, en la mayoría de las figurinas las cabezas son más anchas que largas. Esta tendencia a la "horizontalidad" de las caras las alejaría de la figura humana real.

En cuanto al índice que relaciona el ancho de la cabeza con el ancho de hombros, aquí los resultados demostraron que aquellas figurinas procedentes de distintas zonas de la actual Catamarca en su mayoría poseen cabezas más anchas que sus hombros, rasgo que definitivamente las alejan de las proporciones de la figura humana real. Por otro lado, las figurinas de las zonas de la actual provincia de La Rioja presentaron cuerpos con cabezas más anchas que los hombros y otras con hombros más anchos que la cabeza, por lo tanto, ambas tendencias se encuentran representadas, alejándose y acercándose a la figura humana real. Las piezas de procedencia desconocida, por su parte, se ubicaron dentro de los valores que indican hombros más anchos que cabezas, presentando cuerpos menos plásticos, $\mathrm{o}$ sea con proporciones más cercanas a la figura humana real. Esto podría dar un indicio de cercanía con las que proceden de valles de la actual provincia de La Rioja.

Por último, el índice que relacionó el alto del tocado con el alto de la cabeza arrojó una disposición general para la muestra seleccionada. Hay una tendencia general, sin diferencias significativas entre zonas de procedencia, donde el tocado representa un tercio del total de la cabeza, por lo tanto, se destaca y de este modo dirige la atención a la cabeza.

\section{CONCLUSIÓN}

Los datos obtenidos a partir de la información disponible en las colecciones relevadas indican que, en cuanto a las técnicas seleccionadas para construir los cuerpos, ya sea los tratamientos o los recursos plásticos, habría una uniformidad entre los distintos valles. Por lo tanto, se puede concluir que habría un modo compartido de elaborar los cuerpos. En relación con esto, parecería existir cierta plasticidad en la configuración del cuerpo humano que permite alejarlo o acercarlo a la figura humana real. Esto se demuestra en las partes seleccionadas para armar el cuerpo, pues al parecer bastaría contar con un "núcleo mínimo" determinado por la cabeza y el tronco. Este núcleo sería suficiente para configurar un cuerpo humano expresivo.

La expresividad de los cuerpos se destaca a través de atributos asociados a él, los tocados y peinados hacen que la cabeza destaque como zona expresiva. La presencia de gestos faciales en la mayoría de las figurinas vuelve a enfatizar la importancia de la cabeza. Esto mismo se distingue en relación con sus tamaños, los cuales se encuentran distorsionados. El índice que relaciona el ancho de las cabezas con el ancho de hombros señala cabezas sobredimensionadas, figuras alejadas de la figura humana real.

La alta frecuencia de tocados que se encuentran vuelve a destacar la expresividad a través de la cabeza, mientras que el movimiento del cuerpo imprime dinamismo a estos cuerpos expresivos.

Algunas diferencias entre zonas de origen muestran que aquellas figurinas procedentes de valles ubicados en los actuales territorios de Catamarca configuran cuerpos más plásticos, los cuales pueden alejarse y acercarse de la figura humana real sin perder su núcleo de humanidad. Estas figurinas así mismo presentan movimientos más integrales, a través de gestos faciales, brazos y piernas, o sea donde participan distintas partes del cuerpo. La cabeza se encuentra siempre sobredimensionada, mientras que, en aquellas figurinas procedentes de valles de los territorios de la actual provincia de La Rioja, se observa mayor variabilidad, con cuerpos móviles como más estáticos, cabezas sobredimensionadas y cabezas más pequeñas. Finalmente, en cuanto a las figurinas sin datos, hay tendencias que podrían incluirlas dentro de los grupos de los valles de Catamarca como de los de La Rioja, por lo cual se necesita seguir profundizando en su análisis a fin de poder ubicarlas en algún grupo en particular.

De lo expuesto se puede deducir que hay formas compartidas entre distintas zonas respecto de las técnicas de manufactura, pero se encontrarían algunas diferencias en cuanto a las formas de configurar los cuerpos e imprimirles expresividad. 
Lo que nos presentan estas figurinas antropomorfas son cuerpos plásticos que, a través de un núcleo mínimo de humanidad, representan distintos conceptos de cuerpo vehiculizados en figuras expresivas que se alejan y se acercan de la figura humana real, una plasticidad que tiene siempre como protagonista la cabeza, como representante ideal de la expresividad de estas corporalidades.

Queda entonces para el futuro seguir pensando una metodología más inclusiva, que permita sumar la valiosa información de las figurinas fragmentadas, como así también poder continuar recabando datos más precisos de procedencia, para poder ir delineando formas compartidas o diferenciadas en la forma de construir los cuerpos. En este sentido, también el futuro nos llama a pensar en una arqueología del cuerpo que integre distintas líneas de evidencia y arribar así a los conceptos de cuerpos del pasado y las dinámicas que circularon en poblaciones particulares. De este modo, será posible disponer de un conocimiento más integral de las mismas.

Agradecimientos A Norma Ratto, Mara Basile y Juan Pablo Miyano.

\section{NOTAS}

${ }^{1}(\mathrm{x} 2=16,040, \mathrm{gl} 6, \mathrm{p}=0,014)$.

${ }^{2}$ Un valor mayor a 1: cara más alta que ancha, un valor menor a 1: cara más ancha que alta.

${ }^{3}$ Un valor mayor a 1: cabeza más ancha que los hombros, un valor menor a 1: hombros más anchos que la cabeza.

${ }^{4}$ Un valor mayor a 1: cabeza más ancha que alta, un valor menor a 1: cabeza más alta que ancha.

${ }^{5}$ Valores más cercanos a cero, tocados que menos se destacan con relación al alto total de la cabeza. Para este último índice se ha tomado un $\mathrm{N}$ menor $(\mathrm{N}=46)$ a la muestra total $(\mathrm{N}=105)$, dado que se han considerado solo aquellas figurinas que poseen tocado.

\section{REFERENCIAS}

Alberti, B. 2001. De género a cuerpo: una reconceptualización del cuerpo y sus implicaciones para la interpretación arqueológica. Intersecciones en Antropología 2: 61-72.

Alberti, B. 2007. Destabilizing meaning in anthropomorphic vessels from Northwest Argentina. Journal of Iberian Archaeology 9/10: 209-230.

Aschero, C. 2000. Figuras humanas, camélidos y espacios en la interacción circumpuneña. En Arte en las rocas, menhires y piedras de colores en Argentina, M. M. Podestá \& M. de Hoyos, Eds., pp. 15-44. Buenos Aires: Sociedad Argentina de Antropología.

Bailey, D. 2005. Prehistoric figurines, representations and corporeality in the Neolithic. London: Routledge.

Boric, D. \& RobB, J. 2008 Body theory in archeology. En Past bodies: body-centered research in archaeology, D. Borić \& J. Robb, Eds., pp. 1-7. Oxford: Oxbow Books.

Bugliani, M. F. 2001. Figuras humanas y vasijas: consideraciones sobre la representación humana en la cerámica del formativo en el sur de los valles calchaquíes. En Arqueología Argentina. En los inicios de un nuevo siglo, Publicación del xiv Congreso Nacional de Arqueología Argentina, F. Oliva, N. Grandis \& J. Rodríguez. Eds., pp. 493-511. Rosario: Universidad Nacional de Rosario, Facultad de Humanidades y Artes, Escuela de Antropología $\leq$ http:// naturalis.fcnym.unlp.edu.ar/repositorio/_documentos/ sipcyt/bfa004033.pdf> [consultado: 01-07-2019].

Bugliani, M. F. 2004. Formas y recursos estilísticos para la representación humana durante el Formativo en el Valle de Santa María. Acta Americana 12 (1): 79-88.

Costas, M. P. 2017. El tema de la cabeza antropomorfa en la producción plástica de las sociedades que habitaron el Noroeste Argentino durante el primer milenio DC. Comechingonia 21 (1): 19-38.

GLUzMAn, G. 2010. Representación humana y género en piezas de metal del Noroeste Argentino. Boletín del Museo Chileno de Arte Precolombino 15 (2): 89-106.

GonzÁLEZ, A. R. 1964. La cultura de La Aguada del Noroeste Argentino. Revista del Instituto de Antropología II: 181-236.

GonzÁlez, A. R. 1974. Arte, estructura y arqueología. Buenos Aires: La Marca.

González, A. R. 1998. Cultura La Aguada. Arqueología y diseños. Buenos Aires: Filmediciones Valero.

Gordillo, I. 2009a. Dominios y recursos de la imagen. Iconografía cerámica del valle de Ambato (Catamarca, Argentina). Estudios Atacameños 37: 99-121.

Gordillo, I. 2009b. El sitio ceremonial de La Rinconada. Organización socioespacial y religión en Ambato (Catamarca Argentina). En South American archeology series 7, A. Izeta, Ed., pp. 1-221. Oxford: Bar Publishing.

Joyce, R. 2005. Archaeology of the body. Annual Reviews in Anthropology 34: 139-158.

Joyce, R. 2008. Ancient bodies, ancient lives: sex, gender, and archaeology. Nueva York: Thames and Hudson.

Kusch, M. F. 1990. El concepto de humanidad en la alfarería prehispánica del Noroeste Argentino. Antropología 9: 13-20.

LATour, B. 2004. How to talk about the body? The normative dimension of science studies. Body and Society 10 (2-3): 205-229.

PAstor, S. \& Tissera, L. 2015. Géneros rituales: figuras sexuadas en cerámica y arte rupestre de las Sierras de Córdoba (Argentina). Cuadernos del INAPL 24 (2): 63-86.

Prieto, C. 2017. La personhood en Aguada. Una mirada desde el 
sitio La Rinconada (Departamento de Ambato, Catamarca, Argentina). Saarbrücken: Editorial Académica Española.

Raviña, M. G., Callegari, A. \& Raffino, R. 1998. Corpus Antiquitatum Americanensium. Argentina II, Las figurinas de la Cultura de La Aguada. Buenos Aires: Academia Nacional de la Historia.

Scattolin, M. C. 2005. La mujer que carga el cántaro. En Género y etnicidad en la arqueología sudamericana, V. Williams \& B. Alberti, Eds., pp. 43-72. Olavarria: Serie Teórica $\mathrm{N}^{\circ} 4$, Ediciones INCAUPA.

Scattolin, M. C. \& Bugliani, M. F. 2005. Un repertorio surtido: las vasijas del oasis de Laguna Blanca, puna argentina. Revista Española de Antropología Americana 35: 51-74.
SEMPÉ, M. C. 1975. El canon de la figura humana en el estilo Aguada del NO Argentino. Revista del Instituto de Antropología 2-3: 15-29.

Sofaer, J. 2006. The body as material culture. Cambridge: Cambridge University Press.

Verano, J. 2003. Mummified trophy heads form Peru: diagnostic features and mediocolegal significance. Journal of Forensic Sciences 48: 525-530.

VILAs, L. 2013. El cuerpo presentado y representado. Análisis preliminar de figurinas cerámicas antropomorfas del Departamento de Tinogasta (Catamarca, Argentina). En Delineando prácticas de la gente del pasado: Los procesos socio-históricos del oeste catamarqueño, N. Ratto, Comp., pp. 281-310. Buenos Aires: Serie Publicaciones. Sociedad Argentina de Antropología. 